\title{
XXIX. On acoustic repulsion
}

\section{Dvorák \& Prof. A.M. Mayer}

To cite this article: V. Dvorák \& Prof. A.M. Mayer (1878) XXIX. On acoustic repulsion, Philosophical Magazine Series 5, 6:36, 225-233, DOI: 10.1080/14786447808639500

To link to this article: http://dx.doi.org/10.1080/14786447808639500

$$
\text { 曲 Published online: } 13 \text { May } 2009 .
$$

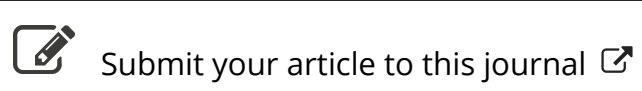

\footnotetext{
Џll Article views: 3
}

Q View related articles ¿ 
fixed stars in our sidereal system are all under each other's influence through gravity. Two stars approaching each other through gravity would at the same time be under the influence of other neighbouring stars, drawing them from the right line towards each other's centre. Therefore they would not collide; but they might approach very near to each other, so as to remain permanently within their powerfully gravitating force, and form a binary system. This is a mode of accounting for the ten thousand double and multiple stars already known, besides the mode of explanation by the nebular theory. Moreover the nebular theory necessarily gives very high velocities to all the stars, but to all in the same direction. If afterwards, by perturbation, they receive contrary directions, still the motions of any two precisely toward one another would be the most improbable of events.

Therefore the mechanical theory of stellar light and heat utterly fails in all its phases. The only true theory for the "ignes æterni" is that of chemical action. This also has been abruptly denied, but only by those entirely unacquainted with the foundations of that theory as explained by myself in "The Origin of the Stars' and in subsequent papers.

XXIX. On Acoustic Repulsion. By V. Dvoß̊ák*. With a Note by Prof. A. M. Małer.

1. ACOUSTIC Repulsion of Resonators which are open at one end only.-In a previous article, "On Acoustic Attraction and Repulsion," I have conclusively proved by theoretic considerations, as well as by experiments, that the average pressure at the node in a column of air vibrating in stationary waves cannot be equal to zero as long as the amplitude of vibration is not infinitely small.

In a resonator open at one end, as, for example, a cylinder, we find a node at the closed end. In the interior of the cylinder near its closed end there exists a greater pressure than on the outer surface of this end which is touched by the outside air, as can easily be shown by means of a sensitive manometer.

To obtain resonance the opening of the cylinder is turned toward the source of the sound ; and the cylinder is then repelled by the excess of pressure within. Resonators not having a cylindrical form, but open at one end, are also subject to such repulsion. In my previous communication I have indicated

* From the American Journal of Science and Arts for July 1878. Translated from the Annalen der Physik und Chemie, Band iii. No. 3; dated Agram, November 19, 1877.

Phil. Mag. S. 5. Vol. 6. No. 36. Sept. 1878. 
means for observing the acoustic repulsion of resonators. As the method described there is not very sensitive, I have replaced it by the following. The resonators here employed are usually made of stiff drawing-paper covered with gum-arabic, and have the shape of a cylinder, with a little paper tube, $h f$, at one end (fig. 1, A). This little tube may also be omitted (as

Fig. 1.

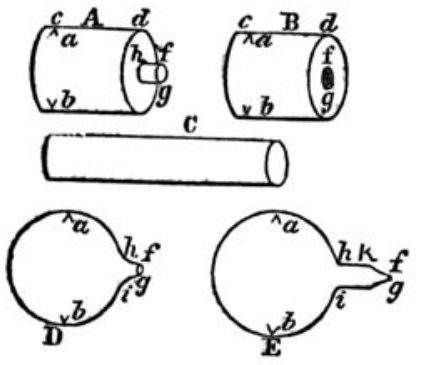

Fig. 2.

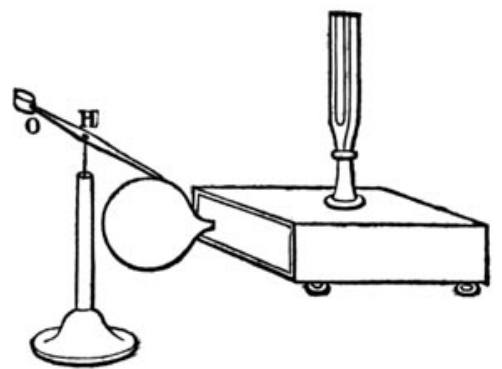

in B): in that case the resonator is tuned by increasing or diminishing the little opening, $f g$. Even a cylindrical tube open at one end, C, may serve our purpose as a resonator. Spherical resonators of glass, D, which a practiced glassblower can make as light as paper resonators, are exoellent. The note of the resonators is determined by gently blowing over the opening or by tapping.

The resonator is fastened with sealing-wax to the end of a light wooden rod, the other extremity of which is provided with a counterpoise of lead, $O$ (fig. 2). The centre of the rod has a glass cap, $\mathrm{H}$, which rests on a needle-point.

The best source of sound is a resonant box of a tuning-fork (fig. 2). The repulsion is so great that it is apparent even with an ordinary brass Helmholtz resonator weighing, with the lead counterpoise, 142 grams*. With every tuning-fork we must first ascertain whether the air in the resonating box vibrates with sufficient energy, because this is not always the case even with accurately tuned boxes. As the elasticity of the different boards which form the elastic system of the box is not equal, their vibrations may hinder the formation of the node at the bottom of the box; in this case the air on the bottom of the box will vibrate but feebly. We can easily ascertain this fact by accurately tuning the box to the note of the fork, and then observing whether the note is considerably weakened by partially covering the opening. If it is not, then the air in the

* The apparatus represented in fig. 3 may also be used to show acoustic attraction by turning the closed end of the resonator toward the box. 
box has but little vibration, even if the tone of the fork is powerful. I have, for example, two boxes with excellent tuningforks by König (of 256 vibrations per second), in which the air would in no wise vibrate powerfully. The strength of the vibration of the air was considerably affected by the degree of tightness with which the fork was screwed to the top of the box. The fork is always vibrated powerfully with a bow; and two bits of rubber tubing must be on the bottom of the box. I generally use the fork $A_{3}$, of 435 vibrations per second, by Konig. Repulsion is then plainly visible with glass resonator at a distance of 10 centimetres from the opening of the box. With a large C fork of König (of 128 vibrations) which sounds for more than ten minutes, it was apparent at a distance of 20 centimetres.

The resonators may be tested either by the reinforcement of the sound produced with a tuning-fork, or by the weakening of the sound on approaching them to the opening of the box* It is not possible to obtain the repulsion of resonators from the prongs of a tuning-fork alone, as their aerial vibrations are too woak (compare Pogg. elvii. p. 42). I formerly tried in vain to obtain acoustic repulsion from vibrating bodies without the aid of resonance. I suspended small resonators before the end of a glass tube vibrating longitudinally, and provided with a cork to increase the vibrating surface. The open end of the resonator was probably too near the end of the fork, and so produced a lowering of the tone and acoustic attraction instead of repulsion. Attraction is probably present in all cases, and can assert itself only when not counteracted by greater repulsiont. Later I obtained repulsion very easily in a longitudinally vibrating glass tube 127 centims. long and 27 millims. in diameter, on the end of which was a cork 46 millims. in diameter. One of the resonators used was spherical (fig. 1, D), and another cylindrical (C).

I also obtained powerful repulsion with a circular disk 31 centims. in diameter and 2 millims. thick, made by König. The plate was fastened in the centre in a vertical position and made to vibrate in six segments, producing a note of 208 vibrations. The resonator was made of stiff paper of the form of $\mathrm{B}$ (fig. 1) ; $a b$ equal 80 millims., $c d 140$ millims., $f g$ equal

* This is perhaps connected with a conversion of the aerial vibrations in the box into the work of repulsion. The vis viva of the sound-vibrations disappears to reappear as work.

$\dagger$ These experiments were also described in a previous communication. In the apparatus represented (fig. 2), repulsion is easily converted into attraction by diminishing the opening of the resonator with wax, and so throwing it out of tune. 
17 millims.; and its opening was placed in front of the centre of a vibrating segment, or ventre.

2. The Acoustic Mill.-A continuous rotation is easily obtained, on the principle of the acoustic repulsion of resonators, by fastening fonr very light paper or glass resonators upon two wooden rods, $o p, q r$ (fig. 3), crossing at right angles, and balanced on a glass cap; all the openings of the resonators fronting one side in the direction of tangents. The whole apparatus is placed before the opening, $K$, of the resonating box and fork, in the manner indicated in fig. 3. The open end $a$ of resonator $I$ is repelled from $K$; the closed end $b$ of resonator 2 is attracted: but in general this attraction does not increase the rapidity of rotation, because it counteracts rotation the moment the resonator (2) has changed its position about $45^{\circ}$. It is therefore not possible to obtain continuous rotation by means of acoustic attraction,

Fig. 3.

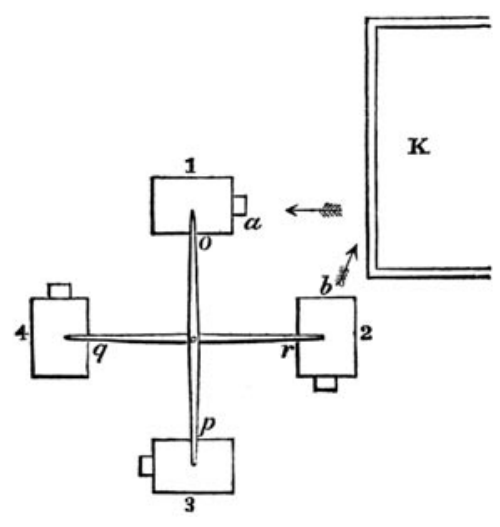
as I have shown by numerous experiments*. The resonator (1) continues to move by reason of its inertia, and resonator (2) takes its place, being in turn repelled, and so on.

A very rapid rotation is obtained by using a large Kundt's tube and placing a small acoustic mill before its open end.

The glass tube (Kundt's), which vibrates longitudinally and produces the tone, is fastened to a heavy table, and protrudes only a short distance through the cork into the glass tube, placed upon a separate table so that its open end projects somewhat beyond the edge of the latter. The length of the rod was 127 centims., the diameter 27 millims.; the half wavelength of its note, $\frac{\lambda}{2}$, equals $10 \frac{1}{2}$ centims. The length of the tube was 45 centims.; the length of the vibrating column of air, corrected for the open end, was $3 \frac{\lambda}{2}+\frac{\lambda}{4}$; the inner diameter was 5 centims.

* Instead of the resonators (fig. 3) I used vertical paper vanes, varying e curvature, without achieving any results, notwithstanding the fact that there was a pretty strong acoustic attraction for each separate vane. 
3. The Acoustic Torsion-balance.-If we hang by a wire a wooden rod provided with a resonator, like the beam of a Coulomb's torsion-balance, in a case having an opening in the side turned toward the resonator, we can compare the intensity of notes having an equal number of vibrations by means of the repulsion of the resonator ; but further experiments are necessary to test the practicability of this method. The sound proceeded from an open pipe, having the note $A$ (of 435 vibrations). To prevent the current of air which passes through the pipe from striking the resonator attached to the balance, we must cut the pipe exactly in the middle of its node, and insert a slack membrane softened with glycerine. To prevent the air issuing from the mouth of the pipe from impinging on the resonator, a broad box is used which surrounds the mouth of the pipe air-tight. This box is open on the side opposite the resonator, so as not to impair the tone. The pipe is sounded by means of a König's acoustic bellows with a uniform blast of air. The distance of the resonator from the mouth of the pipe must be at least 2 or 3 centims., to avoid a change of pitch.

4. Production of Aerial Currents by Sound.-It may easily be proved by simple theoretic considerations that the mean pressure at the node of a column of air is greater than at its ventre; and that it steadily diminishes in passing from the node to the ventre, provided that the amplitude of vibration is not infinitely small.

It would seem that this difference of pressure would be neutralized by the passage of the air from the node to the ventre. There would then be produced a mean pressure in the whole column, which would be greater, however, than that of air at rest; consequently air would issuo from the opening of the ressel in which it forms stationary waves. I have not succeeded, so far, in making the whole process clear; for in reality no perfect balance of pressure takes place. The manometer always shows a slight excess of pressure even at the ventre; but this excess increases as we pass to the node. All my previous experiments indicate moreover that a current of air passes from the node to the ventre, at least in Kundt's tube, in which the air-waves are very powerful. This principal current lasts as long as the air vibrates. Besides, the same experiments show a continuous secondary current, close to the walls of the tube and in a direction contrary to that of the principal current; so that the whole air in the tube is in circulation. The cross section of the principal current is nearly as great as that of the tube, while that of the secondary current is a very narrow ring. 
The excess of pressure as shown by a manometer at the node is always less than the theoretical pressure, because in the latter the air is not supposed to move from the node and to equalize the pressure. Of course the excess of pressure at the ventre is not equal to zero, as theory requires. Probably the friction of the walls bas much to do with these phenomena. It may be expected from what has been said, that the air will issue from the ressel in which it vibrates in stationary waves. The manometer shows, in the first place, that the excess of pressure is not equal to zero in the plane of the opening of a resonator, because a portion of the air immediately in front of this opening partakes of this stationary wave-motion, and because there is always a small excess of pressure even in the ventre of a stationary wave. There is no doubt that a partial equalization of pressure takes place at the opening; experiments show, furthermore, that there is a continuous exit of air, which, as in Kundt's tube, is probably neutralized by a secondary and contrary current.

The exit of the air can easily be proved as follows : a spherical glass resonator is placed before the resonant base of a tuning-fork; the resonator is filled with tobacco-smoke; strong vibrations are given to the fork, when the smoke will be seen to rush from the resonator.

The current of air proceeding from a resonator is well shown by means of a Chladni plate, by means of lycopodium, which accumulates upon the ventres in little heaps when the plate is sounded. If now we place the opening of a bottle (or bottles) of a resonator, D, over such a heap, the lycopodium is immediately blown about in a circle, and may be scattered in any direction by giving suitable inclinations to the resonator. A glass plate held over a heap of lycopodium produces the opposite effect by causing it to contract.

I have succeeded in producing comparatively strong currents of air in still another manner; but $I$ have not yet found an explanation of these complicated phenomena.

A cone made of stiff paper was held with its large end opposite the opening of a large Kundt's tube. The size of this cone may vary; but its effect is greatest when it vibrates to the same note as the Kundt's tube, and so forms a resonator open at both ends; the diameters of its open ends are 37 and 7 millims., and its length 90 millims.

When the Kundt's tube begins to sound loudly, a current of air issues from the narrow end of the cone with such violence that it easily blows out the flame of a candle at a distance of 20 centims. This current rushes through the cone with a peculiar noise, and is easily felt with the finger. 
The cone may be replaced by a cylinder having the width of the Kundt's tube, open at the end turned toward the latter, and closed all but a small hole at the end ; but the current is much weaker; nevertheless it will Fig. 4. move a small wheel with ver-

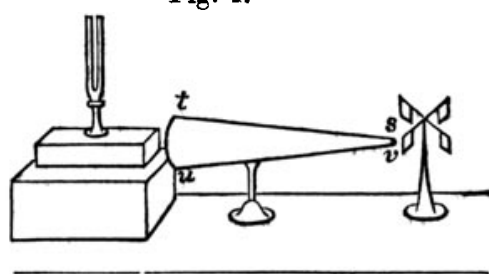
tical paper vanes (fig. 4).

In the experiments with the tuning-forks, it is essential that the cone should vibrate to the same note as the fork; otherwise the current is too weak. For the fork A (of 435 vibrations) the openings of the cone have diameters of 82 and 3 millims., and its length is 373 millims. The opening at the apex of the cone must be very small to obtain an appreciable current.

On conclusion of this investigation, Dr. R. König kindly communicated to me that Mr. Alfred Mayer in New York [Hoboken] had previously succeeded in producing continuous rotation by means of sound: The communication was as follows :- " Professor A. M. Mayer showed me a very similar experiment last summer (1876). He suspended by a thread two large well-tuned flasks attached to a rod, and caused the whole apparatus to revolve by means of a tuning-fork. I informed him in consequence that you had previously demonstrated the phenomena of repulsion in resonators; for he was not acquainted with your paper* on acoustic attraction and repulsion."

Note by Professor Alfred M. Mayer.-My connexion with the discovery of the sound-mill is as follows :-

In January 1876 I made the discovery (first reached by theoretic deductions) that there was more pressure on the inner surface of the bottom of a resounding cavity than on the outer surface of the bottom, which touches the outer air. I subsequently proved the truth of this conclusion by experiments on suspended resonators, and by observations on the motions of precipitated silica powder and films of soap-bubbles placed at various points in resonators of different forms. My first publication of these results was on May 22, 1876, on which day I read a paper on this discovery before the New-York Academy of Sciences, and exhibited before the members an apparatus formed of two + arms of light wood, with a resonator attached to each arm, as in fig. 3 of Professor Dvorák's paper. On sounding an organ-pipe, or a fork on its resonant box, in tune with these resonators, they were successively repelled from the

* Read before the Royal Academy of Sciences, Vienna, in 1875. 
pipe, or fork, and a continuous rotation was exhibited. At the same meeting this experiment was preceded by those on the motions of silica-powder \&c. in resonators.

On the 8th of July, 1876, there appeared in the "Scientific American' a report of this meeting of the Academy, in which my experiments on Acoustic Repulsion are thus referred to :-

"In the next place, Professor Mayer exhibited an apparatus constructed by him to produce motion by means of soundpulses. Four glass resonators on cross-arms were suspended by means of a string. On sounding an organ-pipe in tune with the resonators and bringing it opposite the mouth of one of them, the resonator was repelled and the apparatus commenced to rotate. This experiment was the more striking from the fact that, so far from any current of air proceeding out of the mouth of the organ-pipe, the air is actually sucked in, as may be rendered visible by means of smoke from a cigar. The smoke is carried up the pipe even when the latter is closed at the top with cotton wool so as to smother the sound. On substituting disks of cardboard for the resonators, they were drawn up to the mouth of the organ-pipe with considerable force. When fine silica-powder was placed in the resonators, it was thrown into violent motion on sounding the pipe."

In the same month (July 1876) Dr. Rudolph König visited me, and I exhibited the same experiments before him.

The discovery of the acoustic repulsion of resonators and the invention of the sound-mill were made independently by Professor Dvorák and myself. It is another instance of men, even so far distant as Agram and Hoboken, led into the same path of research by the natural growth of science.

Dimensions of the resonators and reaction-wheels used, in millimetres:-

(1) Fork $\mathrm{C}$, of 128 vibrations. Glass resonator of form $\mathrm{E}$ (fig. 1), $a b$ equalled $90 ; h i, 25 ; h k, 20 ; k f, 33 ; f g, 8$. Its weight, together with its leaden counterpoise, was 70 grams.

(2) Fork A, 435 vibrations per second. (a) The glass resonator used in the experiment represented in fig. 2 , and to show the current of air by means of smoke, was of the form $D$ (fig. 1) : $a b$ equalled $58 ; h f, 22 ; f g, 10 . \quad(b)$ The glass resonators of the acoustic mill were of the form $\mathrm{D}: a b$ equalled $34 ; h f, 12 ; f g, 3$. The length of the arms from the middle of the glass cap to the middle of the resonator was 52 millims. The weight of the whole wheel was 23 grams. (c) Paper resonators of the acoustic mill (fig. 3) were of the form A (fig. 1): $a b$ equalled $34 ; c d, 50 ; h f, 6 ; f g, 9$. The length of the arms was 65 millims., the weight of the whole wheel 9 grams. 
(3) Kundt's tube, $\frac{\lambda}{2}$ equals 105 millims. The glass resonators of the acoustic mill were of the form $\mathrm{D}$ (fig. 1): $a b$ equalled $24 ; h f, 2 ; f g, 7$; length of the arms 30 millims.

It is a striking fact that very small resonators may give a very deep note: with fork $A$, I used a glass resonator of the form $\mathrm{D}$ (fig. 1), in which $a b$ equalled $24, h f 14$, and $f g 1$ millim. The volume was about ninety times less than that of the resonant box of the fork, to whose note the resonator was tuned. Notwithstanding its smallness it showed acoustic repulsion.

XXX. Proceedings of Learned Societies.

\section{GEOLOGICAL SOCIETY.}

[Continued from p. 153.]

June 5, 1878._John Evans, Esq., D.C.L., F.R.S., Vice-President, in the Chair.

THE following communications were read:-

1. "On the Quartzites of Shropshire." By Charles Callaway, Esq., M.A., B.Sc., F.G.S.

In a former paper (Q.J. G. S. xxxiii. p. 652) the author indicated that part of the so-called quartzites of the Wrekin are "Hollybush Sandstone ;"- in the present communication he shows that the whole, both in the Wrekin and Church-Stretton areas, are of Cambrian or Precambrian and not of Caradoc age.

In the Wrekin area the quartzites rest unconformably against the volcanic axis in a nearly continuous band, dipping a way from it at angles of from $30^{\circ}$ to $55^{\circ}$, their present position being due to its elevation. The volcanic rock is a bedded Precambrian tuff, which reappears in Lawrence Hill and the Ercal, also accompanied by quartzites overlain by Hollybush Sandstone. Caer Caradoc belongs to the same volcanic series; and the quartzites reappear on its S.E. flank, overlain by Hollybush Sandstone containing Kutorgina cingulata and Serpulites fistula, above which follow the Shineton Shales, and next, separated by a fault, the Hoar-Edge grits (Lower Caradoc). The author believes that the apparently conformable succession here is due to parallel faults. Along the S.E. flank of the Wrekin the quartz rock dips S.E., while the volcanic rocks dip N., and fragments of the latter are contained in its base. The author is inclined to consider this a friction-breccia, and the junction a faulted one. He also regards the junction with the Hollybush Sandstones as a faulted one, and maintains that in any case the quartzites are older than the latter rocks, which are sometimes considered the equivalents of the Ffestiniog group, and by Mr. Belt to be Menevian. The quartzites can hardly belong to any part of the Upper Cambrian; and the author passes on to consider the various positions which they may be held to occupy, and gives reasons for thinking that they are Pre- 